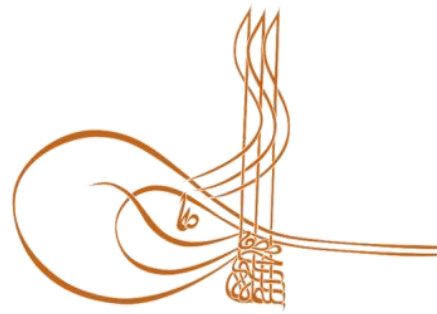

www.turkishstudies.net/economy
Turkish Studies - Economics, Finance, Politics

eISSN: $2667-5625$

Research Article / Araștırma Makalesi

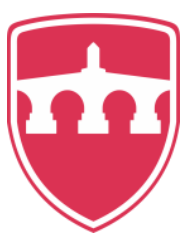

INTERNATIONAL BALKAN

UNIVERSITY

Sponsored by IBU

\title{
Algılanan Örgütsel Destek ile Algılanan İş Performansı Arasındaki İlişkide İş Tatmininin Aracı Rolü
}

\author{
The Mediating Role of Job Satisfaction in the Relationship Between Perceived Organizational \\ Support and Perceived Job Performance
}

\section{Burcu Tosun*}

\begin{abstract}
Employees' sense of getting supported by their organizations they work has an important role in increasing their job satisfaction (Eisenberger et al., 1997). According to Social Exchange Theory (Blau, 1964) under certain circumstances, individuals try to respond by being beneficial to their persons or organizations which benefits them. Confirming this theory, some researches found out that employees with high job satisfaction levels tend to increase their performance as a reflection of their happiness (eg. Judge et al., 2001; Fisher, 2003). Depending on the same theory, the employees who believe to be supported by their organizations are expected to increase their performance and this expectation is confirmed by various studies (eg. Byrne and Hochwarter, 2008; Riggle et al., 2009). Similarly, organizational support perception of employees make them believe that their increasing performance can be seen and rewarded by the organization and this belief encourages them to perform more (Guan et al., 2014). Depending on the expectation of the interaction among three variables based on Social Exchange Theory and the inadequacy of researches about that interaction, this study aims to make a contribution to the literature and present a perspective for the future researches. In this concept, besides the relationships mentioned above, this study also investigates the mediating role of job satisfaction in the relationship between perceived organizational support and perceived job performance, which is not evaluated enough in the academic literature before. In the present research, the data were gathered from 253 participants who are the employees of a private hospital located in Ankara, Turkey. The results of the analysis showed that perceived organizational support had a positive and significant effect on both job satisfaction and perceived job performance. Job satisfaction was also found to be positively and significantly related to perceived job performance. The results also indicated that job satisfaction fully mediated the relationship between perceived organizational support and perceived job performance.
\end{abstract}

Structured Abstract: Introduction and the Aim of the Study The results of Hawthorne studies made researchers aware of the positive and negative effects of emloyees' perceptions and emotions on their job performance and indicated a link between work related attitudes and productivity. Since that time, all perceptional factors and attitudes affecting job performance are being examined in detail with an increasing

\footnotetext{
* Öğr. Gör. Dr. Atılım Üniversitesi, İşletme Fakültesi, İşletme Bölümü

Lec., PhD. Attlim University, Faculty of Management, Department of Management ORCID 0000-0002-8030-7066

burcu.tosun@atilim.edu.tr

Cite as/ Atıf: Tosun, B. (2020). Algılanan örgütsel destek ile algılanan iş performansı arasındaki ilişkide iş tatmininin arac1 rolü, Turkish Studies - Economy, 15(1), 541-555. https://dx.doi.org/10.29228/TurkishStudies.41563
Received/Geliș: 31January/Ocak 2020
Accepted/Kabul: 25 March/Mart 2020
Checked by plagiarism software
Copyright $(C)$ INTAC LTD, Turkey 
importance (Guan et al., 2014). Job satisfaction and perceived organizational support which is assumed to be an antecedent of job satisfaction are included among the popular research variables, since they are expected to be important determinants of performance and productivity.

According to Social Exchange Theory (Blau, 1964), under certain circumstances, individuals try to respond by being beneficial to their persons or organizations which benefits them. Consistently, employees try to respond positively and beneficially when they believe that they receive a strong support from their organizations (eg. Eisenberger et al., 1986; Shore and Wayne, 1993). That respond usually activates positive work related attitudes and finally increases job performance (Miao and Kim, 2010). Similarly, the ones who believe that they cannot get sufficient support from their organizations tend to display negative attitudes leading to decreased job performance (Eisenberger vd., 1997). According to the meta-analysis which evaluates 70 different studies in the field done by Rhoades and Eisenberger (2002), there is a strong relationship among perceived organizational support, job satisfaction and job performance and perceived organizational support is one of the important antecedents of job performance.

In this present study, the relationship and the interaction among perceived organizational support, job satisfaction and job performance was examined based on the perspective of previous literature. In order to examine the variables, nurses and health support assistants working in a private hospital were chosen as participants. Tha aim of the study was evaluating the relationship between perceived organizational support and job satisfaction; the link between job satisfaction and job performance; the effect of perceived organizational support on job performance and finally the role of job satisfaction in the relationship between perceived organizational support on job performance, in helath workers. The findings are expected to contibute to the literature of the field.

\section{Theoretical Background}

Perceived organizational support is the extent of belief that employees have, about how important their wellfare and happiness is for the organization and how much they are appreciated for their individual contributions (Eisenberger et al., 1986:500; Rhoades and Eisenberger, 2002:703). In other words, perceived organizational support is the reflection of employees' evaluation about how much the organization is "on their sides" (Witt and Carlson, 2006:347).

Job satisfaction refers to an individual's pleasure about his job or the positive feelings he has about his job (Locke, 1976). Williams and Podsakoff (1989:252) defines the concept as an emotional reaction caused by performing job tasks. According to Spector (1997:2), job satisfaction is the reflectşon of how much the employees like their jobs.

Rousseau and McLean (1993:21) defined job performance as the effort which employees have to display in return for the payments they get. Job performance is also described as the aggregate behaviors consistent with the objectives and expectations of the organization, that have to be executed in the work place by the employees (Williams, 2002:33).

\section{Hypothesis Development}

Examining the past literature, various studies can be found which confirm the relationship between perceived organizational support and job satisfaction (eg. Eisenberger et al., 1997; Kwak et al., 2010; WannYih and Htaik, 2011); job satisfaction and job performance (eg. Heskett et al., 1994; Judge et al., 2001; Fisher, 2003); perceived organizational support and job performance (eg. Rhoades and Eisenberger, 2002; Byrne ve Hochwarter (2008).

On the way to organizational support perception to increasing job performance, it seems possible that first job satisfaction might increase and that increase might cause the improvement of job performance. The research about this interaction is insufficient in the literature. Thus, to make a contribution to the literature in the field, the hypotheses below are developed:

H1: There is a positive and significant relationship between perceived organizational support and perceived job satisfaction.

$\mathrm{H} 2$ : There is a positive and significant relationship between job satisfaction and perceived job performance.

Turkish Studies - Economy, 15(1) 
H3: There is a positive and significant relationship between perceived organizational support and perceived job performance.

H4: Job satisfaction has a moderating role in the relationship between perceived organizational support and perceived job performance.

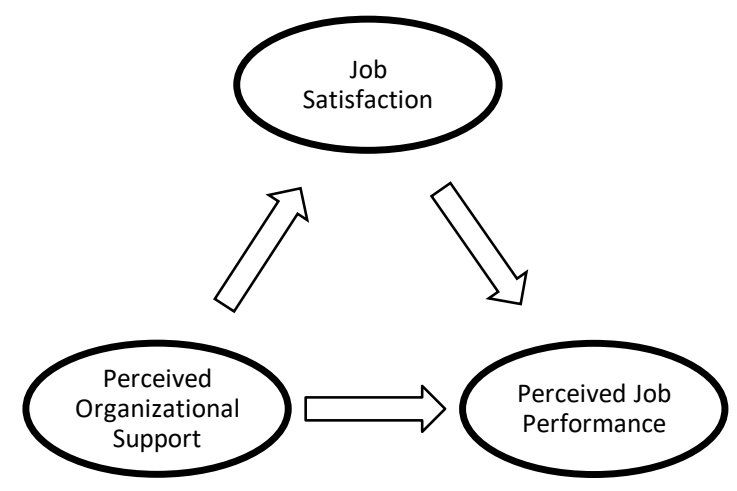

\section{Method of the Study}

In order to test the hypotheses, 253 participants including nurses and helath support assistans working in a private hospital in Ankara, Turkey, were chosen as the sample. Perceived organizational support was meaured by a 4-itemed scale developed by Rhoades et al. (2001) and responded by 5 point Likert scale. Job satisfaction level of participants was measured by the scale recommended by Scarpello ve Campbell (1983), which includes a single question "Considering everything, how satisfied are you with your job?". This question was also responded by 5 point Likert scale. Finally, 4-itemed perceived job performance self-report scale which is developed by Darwish (2000) was responded by 5 point Likert scale. The scales were found to be reliable (Cronbach's alpha values are 0.95 and 0.77 ). Correlation and hierarchical regression analyses are done in order to test hypotheses.

\section{Results and Discussion}

The first hypothesis which puts forward that, there is a positive and significant relationship between perceived organizational support and perceived job satisfaction, is confirmed $(\beta=0,537 ; p=0,000)$. The second hypothesis which claims that, there is a positive and significant relationship between job satisfaction and perceived job performance, is confirmed $(\beta=0,343 ; p=0,000)$. The third hypothesis which suggests that, there is a positive and significant relationship between perceived organizational support and perceived job performance, is also confirmed $(\beta=0,132 ; p=0,036)$. And the last hypothesis, which claims that, job satisfaction has a moderating role in the relationship between perceived organizational support and perceived job performance, comes out to be true. Since the relationship between perceived organizational support and perceived job performance becomes insignificant $(\mathrm{p}=0,296>0,05)$, there seems to be job satisfaction has a complete medaition effect in the relationship between perceived organizational support and perceived job performance.

Social Exchange Theory (Blau, 1964) depends on the reciprocity between employee-organization relationship. When employees feel to be supported by their organizations, their job satisfaction level increases and as a response to that satisfaction and support, they put more effort in order to meet the expectations and become more beneficial to the organization. This description seems to be a perception-attitude-behavior chain which is consistent to reciprocity principle of Social Exchange Theory.

Keywords: Perceived Organizational Support, Job Satisfaction, Perceived Job Performance, Social Exchange Theory, Mediation Analysis

Öz: Bireylerin çalıştıkları kurumlardan destek aldıklarını hissetmeleri iş tatminlerini arttırmada önemli bir rol oynamaktadır (Eisenberger vd., 1997). Sosyal Değişim Teorisi'ne göre (Blau, 1964) belirli koşullar altında, 
bireyler fayda gördükleri kişi ve örgütlere faydalı olarak karşılık verme çabası içine girmektedirler. Bu teoriyi doğrular şekilde, iş tatmini yüksek olan çalışanların işlerinden duydukları memnuniyetin bir yansıması olarak performanslarını arttırdıkları yapılan bazı çalışmalar sonucunda ortaya konmuştur (örn: Judge vd., 2001; Fisher, 2003). Yine Sosyal Değişim Teorisi'nden yola çıkarak, çalıştığı örgüt tarafından desteklendiğine inanan çalışanların performans arttırma çabasına girmeleri de beklenmekte ve yapılan çeşitli çalışmalar sonucunda da bu beklenti doğrulanmaktadır (Örn: Byrne ve Hochwarter, 2008; Riggle vd., 2009). Benzer şekilde, algılanan örgütsel destek, çalışanların artan performanslarının örgüt tarafindan görüleceği ve ödüllendirileceğine dair inançlarını beslemekte ve bu durum da çalışanları daha çok performans sergilemeye teşvik etmektedir (Guan vd., 2014). Sosyal Değişim Teorisi’nin bakış açısına göre söz konusu üç değişkenin etkieşim içinde olacağı öngörüsünden ve bu değişkenlerin birlikte değerlendirildiği araştırma sayısındaki yetersizlikten de yola çıkarak, bu çalışma ile literatüre bir katkı ve gelecek çalışmalara bir perspektif sunmak amaçlanmıştır. Bu bağlamda yukarıda sıralanan beklenen ilişkilerin yanı sıra, akademik literatürde daha önce yeteri kadar değerlendirilmemiş olan, algılanan örgütsel destek ile iş performansı arasında iş tatmininin aracılık rolü özellikle araştırılmıştır. Ankara'da özel bir hastanede 253 katılımcı üzerinde gerçekleştirilen araştırma sonuçlarına göre, algılanan örgütsel desteğin iş tatmini ve algılanan iş performansı üzerinde anlamlı ve olumlu bir etkiye sahip olduğu ve aynı zamanda iş tatmininin de algılanan iş performansı üzerinde anlamlı ve olumlu bir etkiye sahip olduğu ortaya konmuştur. Ayrıca, algılanan örgütsel desteğin algılanan iş performansı üzerindeki etkisinde iş tatminin tam aracı rolüne sahip olduğu da belirlenmiştir.

Anahtar Kelimeler: Algılanan Örgütsel Destek, İş Tatmini, Algılanan İş Performansı, Sosyal Değişim Teorisi, Aracilik Analizi

\section{Giriş}

Çalışanların algı ve duygularının iş performanslarına olan olumlu ve olumsuz etkilerinin anlaşılmaya başlandığı Hawthorne çalışmalarından elde edilen sonuçlar, iş yerindeki tutumlar ile üretkenlik arasında bir bağlantı olduğunu ortaya koymuştur. $\mathrm{O}$ zamandan bu yana, iş performansına etki eden tüm algısal faktörler ve tutumlar her geçen gün artan bir önemle ve titizlikle araştırılmaya devam edilmektedir (Guan vd., 2014). Günümüz koşullarının bir sonucu olan rekabetçi ve dinamik çevrelerde var olma çabası gösteren işletmeler, çalışanlarının performanslarını etkileyen tüm faktörleri değerlendirme çabası içindedirler. Bu kapsamda ele alınan önemli konuların arasında, iş tatmini ve bu tatminin öncülleri arasında olduğu düşünülen algılanan örgütsel destek kavramı araştırmacılar tarafından uzun yıllardır ilgi görmektedir. Özellikle iş tatmini ile performans arasındaki ilişki sürekli irdelenmeye devam edilmektedir. Bireylerin iş tutumları başta iş performansları olmak üzere iş yerindeki davranışlarını etkilemektedir (Judge vd., 2001).

Blau'nun (1964) Sosyal Değişim Teorisi'ne göre, belli şartlar altında insanlar kendilerine fayda gösterenlere karşılık verme çabası içine girmektedir. Bu durumda çalışanlar örgütlerinden güçlü bir destek algıladıklarında, olumlu ve faydalı yönde karşılık vermeye çalışmaktadır (Örn., Eisenberger vd., 1986; Shore ve Wayne, 1993). Bu karşılık genellikle iş tatmini gibi olumlu iş tutumlarını arttırmaya sebep olmakta ve en nihayetinde performans artışı şeklinde kendini göstermektedir (Miao ve Kim, 2010). Benzer şekilde örgütleri tarafından yeterli destek göremediğini hisseden çalışanlar ise performans düşüklügüne kadar varan olumsuz iş tutumları sergilemektedir (Eisenberger vd., 1997). Rhoades ve Eisenberger (2002)'in gerçekleştirdikleri alanda yapılmış 70 farklı çalışmayı değerlendiren meta-analize göre, algılanan örgütsel destek, iş tatmini ve iş performansı arasında güçlü bir ilişki söz konusudur ve algılanan örgütsel destek iş performansının önemli öncüllerinden birisidir.

$\mathrm{Bu}$ çalışmada da algılanan örgütsel destek, iş tatmini ve algılanan iş performansı ele alınmış; geçmiş literatürün 1şı̆̆ında bu değişkenlerin birbirleriyle olan etkileşimi incelenmiş ve özel bir hastanede çalışan hemşire ve sağlık destek personeli örneklem olarak alınarak, bu değişkenler arasındaki ilişkiler analiz edilmiştir. Bu araştırma vesilesi ile sağlık çalışanlarının algıladıkları örgütsel destek ile iş tatminleri arasındaki ilişkiyi değerlendirmek, algıladıkları örgütsel destek ile iş performansları arasındaki bağlantıyı incelemek, iş tatminlerinin iş performanslarına yansımalarını 
ele almak ve algıladıkları örgütsel destek ile iş performansları arasındaki ilişkide iş tatmin durumlarının etkisini tespit etmek hedeflenmiştir. Çalışma bulgularının literatüre bahsedilen konularda katkıda bulunması umulmaktadır.

\section{Kavramsal Çerçeve}

\subsection{Algılanan Örgütsel Destek}

Örgütsel destek teorisi çalışanların örgütlerinin kendilerine birey olarak ne kadar kaynak ve değer sağladıklarına, performanslarını ne ölçüde ödüllendirdiklerine ve zor zamanlarında kendilerine ne kadar yardım ettiklerine dair genel bir izlenim ve görüşleri olduğunu öne sürer (Eisenberger vd. 1986:500; Shore ve Shore, 1995:151; Rhoades ve Eisenberger 2002:703). Bu izlenim ve görüşlerin olumlu yönde olması hem örgüt hem de çalışanlar açısından istenen çıtıtılar elde edilmesine yol açmaktadır (Rhoades ve Eisenberger, 2002).

Algılanan örgütsel destek, çalışanların örgütlerinin kişisel katkılarına değer verdiği, refah ve mutluluklarını önemsediğine dair inançlarının derecesidir (Eisenberger vd., 1986:502; Rhoades ve Eisenberger, 2002:703). Bir başka deyişle, algılanan örgütsel destek, çalışanın örgütün ne kadar "kendi tarafinda" olduğuna dair değerlendirmesini yansıtmaktadır (Witt ve Carlson, 2006:347). Bu değerlendirme, çalışanlarda örgütün iyiliğini düşünmek ve amaçlarına ulaşmasına yardım etmek konusunda bir zorunluluk hissi yaratır. Aynı zamanda, algılanan örgütsel desteğin verdiği önemsenme, onaylanma ve saygı duyulma hissi çalışanların sosyal ve duygusal ihtiyaçlarını tamamlamalarını sağlamakta ve onların örgütsel kimlikleri ile sosyal kimliklerini özdeşleştirmelerine yardımcı olmaktadır (Rhoades ve Eisenberger, 2002:703).

\section{İş Tatmini}

Çok basit bir tanımlamayla, iş tatmini bir bireyin işinden olan memnuniyetini veya işi hakkında sahip olduğu olumlu duyguları ifade etmektedir (Locke, 1976:1304). Aynı zamanda işle ilgili görevleri yerine getirmekten kaynaklanan duygusal bir tepki olarak da tanımlandırılmaktadır (Williams ve Podsakoff, 1989:252). Spector'a (1997:2) göre ise, iş tatmini çalışanların işlerini ne kadar sevdiğinin bir yansımasıdır. Spector (1985) ilerleyen zamanlarda iş tatminini çok boyutlu bir kavram olarak değerlendirerek, ücret, terfi, yönetim, maaş dışı verilen haklar, durumsal ödüller, işletim prosedürleri, iş arkadaşları, işin doğası ve iletişimi kapsayan çalışan tutumları olarak daha kapsamlı bir şekilde nitelendirmiş̧ir. Hulin ve Judge (2003:261) ise, iş tamininin bir bireyin işine karş1 verdiği çok boyutlu psikolojik tepkiler içerdiğini ve bu tepkilerin tüm tutumlarda olduğu gibi bilişsel, duygusal ve davranışsal bileşenleri olduğunu ifade etmişlerdir.

Oldukça eskiye dayanan iş tatmini literatüründe, iş tatmininin pek çok değişken tarafından etkilendiği görülmektedir. Mullins'e göre (1996), cinsiyet, yaş, kişilik, yetenek, uyumluluk gibi bireysel faktörler; iş arkadaşlarıyla kurulan ilişkiler, grup normları ve dinamikleri ve iletişim imkânları gibi sosyal faktörler; inanç ve değerler gibi kültürel faktörler; örgütün yapısı, kural ve politikaları gibi örgütsel faktörler ile politika, ekonomi, teknoloji gibi çevresel faktörler, çalışanları iş tatminini etkilemektedir.

\section{2. İş Performansı}

Rousseau ve McLean (1993:21) iş performansını basit bir ifadeyle, çalışanların aldıkları ücrete karşılık olarak göstermek zorunda oldukları gayret olarak tanımlamışlardır. İş performansı, bir çalışanın iş tanımına göre belirlenmiş ve gerekli olan, aynı zamanda da örgüt tarafından zorunlu kılınan, takdir edilen ve ödüllendirilen aktiviteler olarak da tanımlandırılabilir (Janssen vd., 2004:132). Bir diğer tanıma göre de, iş performansı örgütün amaç ve beklentilerine uygun olan ve iş ortamında sergilenmesi gereken davranışlar bütünü olarak ifade edilmektedir (Williams, 2002:33).

Kurallar ve prosedürler iş davranışlarını beklentiler çerçevesine sokmakta ve böylece temel örgütsel görevler örgütsel amaçlara ulaşabilmek için koordine ve kontrol edilebilmektedir. 
Çalışanların iş aktivitelerinde ve iş rollerinde yeterli olması iş performansının en önemli ölçütlerinden birisidir (Borman ve Motowidlo, 1993:71-98).

\section{Hipotez Geliştirme ve Araştırmanın Modeli}

Bireylerin çalıştıkları örgütler tarafından desteklendiklerini hissetmesi durumunda, iş memnuniyetlerinin artması genel mantık çerçevesinden beklenen bir durumdur. Aynı mantıkla yola çıkan araştırmacılar, bu konu üzerine çeşitli çalışmalar yaparak, söz konusu ilişkinin varlığını sorgulamışlardır.

Geçmiş literatür incelendiğinde, algılanan örgütsel destek ile iş tatmini arasında anlamlı ve olumlu yönde ilişkiler bulunduğunu gösteren örneklerle sıklıkla karşılaşılmaktadır. Ahmad ve Yekta (2010) çalışmalarında algılanan örgütsel destek ile iş tatmini arasında anlamlı bir ilişki olduğunu göstermişlerdir. Ehsani ve diğerleri ise (2013) araştırmalarında çalışanların algıladıkları örgütsel destek ile hem iş tatmini hem de örgütsel bağl1likları arasında bağlantı olduğu sonucuna varmışlarıdır. Eisenberger ve diğerleri (1997) da algılanan örgütsel destek ile iş tatmini arasında bir bağlantı olduğunu ifade etmişlerdir. Kwak ve diğerleri (2010) ise algılanan örgütsel destek yokluğunda iş tatminsizliğinin arttığını tespit etmişlerdir. Rutherford ve diğerleri (2009) de benzer şekilde algılanan örgütsel destek ile iş tatmininin olumlu bir şekilde bağlantılı olduğunu ifade etmişlerdir. Wann-Yih ve Htaik (2011) de yaptıkları çalışmada algılanan örgütsel destek ile iş tatmini arasında olumlu bir ilişki bulunduğunu göstermişlerdir. Geçmişte yapılan bu tür çalışmaların 1şığı altında ve yukarıda anlatılan teorik bilgilerin değerlendirilmesi sonucunda aşağıdaki hipotez geliştirilmiştir:

H1: Algılanan örgütsel destek ile iş tatmini arasında olumlu ve anlamlı bir ilişki vardır.

İş tatmini ve iş performansı bağlantısı, örgütsel davranış literatüründe en eski araştırma konularından birisidir. Dolayısıyla örgütsel davranış literatüründe uzun yıllardır iş tatmini ile iş performansı arasındaki ilişki defalarca araştırılmış, pek çoğunda ikisinin arasında olumlu bir ilişki olduğuna dair kanıtlar elde edilmiştir (örn.: Smith ve Cranny, 1968; Mirvis ve Lawler, 1977).

Herhangi bir sosyal etkileşimde insanlar verdikleri girdi ile aldıkları çıktıyı ve kendi gösterdiği çaba ile karşı tarafın gösterdiği çabayı karşılaştırır. Bir taraf diğerine yardım ettiği zaman, yardım alan taraf yardım eden tarafa sempati duyar ve karşılığında yardım etmeye çalışır (Walster ve ark., 1973). Örgütsel destek teorisine göre, algılanan örgütsel destek sosyo-duygusal ihtiyaçlarını karşılasa da, övgü ve onaylanma ihtiyacı devam etmektedir. Algılanan örgütsel destek performansödül beklentilerini arttırabilmekte ve/veya yardım etme hevesi verebilmekte, böylelikle de genel iş tatminine katkıda bulunabilmektedir (Eisenberger vd.,1986; Guan ve ark., 2014).

Organ (1977) da iş tatmin düzeyi yüksek olan çalışanların çalıştıkları örgütlerin etkinliğini artırmaya yönelik davranışlar gösterme eğiliminde olduklarını belirtmiştir. Literatüre bakıldığında iş tatmininin iş performansıyla olan olumlu ilişkisinin pek çok çalışma tarafindan desteklendiği görülmektedir (Örn: Heskett vd., 1994; Judge vd., 2001; Fisher, 2003; Christen vd.,2006). Geçmişte yapılan bu tür çalışmaların ışığı altında ve yukarıda anlatılan teorik bilgilerin değerlendirilmesi sonucunda aşağıdaki hipotez geliştirilmiştir:

$\mathrm{H} 2$ : İş tatmini ve algılanan iş performansı arasında olumlu ve anlamlı bir ilişki vardır.

Algılanan örgütsel destek ile iş performansı arasındaki ilişki genellikle Blau'nun (1964) Sosyal Değişim Teorisi ile açıklanmaktadır. Bu bağlamda değerlendirildiğinde, çalıştıkları örgütten destek gördüklerine inanan bireylerin, bu iyiliğe örgütün amaçlarına ulaşması için benzer şekilde destek vererek karşılık vermeye çalıştıkları düşünülmektedir. Bu bakış açısına göre, örgütsel desteği yüksek algılayan çalışanların, iş performanslarının yüksek olmasını beklemek mümkündür. Algılanan örgütsel desteğin yüksek düzeyde olması, güven duygularının oluşmasını sağlamakta ve beraberinde örgütsel özdeşleşme ile uzun vadeli yükümlülükler getirmektedir (Rhoades ve 
Eisenberger, 2002). Algılanan örgütsel desteğin en önemli çıktıları ise daha düşük istenmeyen davranış (geri çekilme davranışı) ve daha yüksek iş performansı olarak görülmektedir (Rhoades ve Eisenberger, 2002).

Rhoades ve Eisenberger'in (2002) meta-analizinde, algılanan örgütsel desteğin iş performansıyla olumlu yönde ilişkili olduğuna dair yapılan pek çok çalışma göze çarpmaktadır (Örn: Armeli vd., 1998; Eisenberger vd., 1986; Eisenberger vd., 1990). Byrne ve Hochwarter (2008) yaptıkları çalışmada, algılanan örgütsel destek ile iş performansı arasında orta düzeyde bir ilişki olduğunu tespit etmiştir. Aynı şekilde, Riggle ve diğerleri (2009) da yaptıkları meta-analizde algılanan örgütsel destek ile iş performansı arasında orta düzeyde bir ilişki olduğunu vurgulamışlardır. Geçmişte yapılan bu tür çalışmaların ışığı altında ve yukarıda anlatılan teorik bilgilerin değerlendirilmesi sonucunda aşağıdaki hipotez geliştirilmiştir:

H3: Algılanan örgütsel destek ile iş performansı arasında olumlu ve anlamlı bir ilişki vardır.

Algılanan örgütsel destek, iş tatmini ve iş performansının birbirleriyle yakından ilişkili olduğu literatür taramalarında göze çarpmaktadır (örn: Miao ve Kim, 2010). Yukarıda da anlatıldığg üzere, geçmiş literatür üç değişkenin de birbirlerine etkisi olduğunu doğrular niteliktedir. Tüm bu bilgilerin ışığında, algılanan örgütsel desteğin, iş performansına olan etkisinde iş tatmininin bir rolünün olup olmadığına dair literatürde fazla çalışma bulunmamaktadır. Mevcut bazı çalışmalarda da üç değişken bir arada değerlendirilmekle birlikte (örn: Miao ve Kim, 2010), aracılık veya moderatörlük etkileri üzerinde pek durulmamıştır. Çalışanın örgütünden destek aldığı algısına sahip olmasından, performansını arttırmasına giden yolda, önce iş tatmininin yükselmesi ve bu tatminin de performansın olumlu yönde değişmesine sebep olabilmesi mantıken mümkün olan ve araştırılması gereken bir konudur. Bu konuda yapılmış çalışmaların yetersiz olmasından hareket ederek, literatüre bu konuda bir katkı da sağlamak amacıyla, algılanan örgütsel destek ile iş performansı arasındaki ilişkide iş tatmininin aracı rolünü sorgulamak üzere aşağıdaki hipotez geliştirilmiştir:

H4: Algılanan örgütsel destek ile iş performansı arasındaki ilişkide iş tatmini aracı rolü oynamaktadır.

Şekil 1: Araştırmanın Modeli

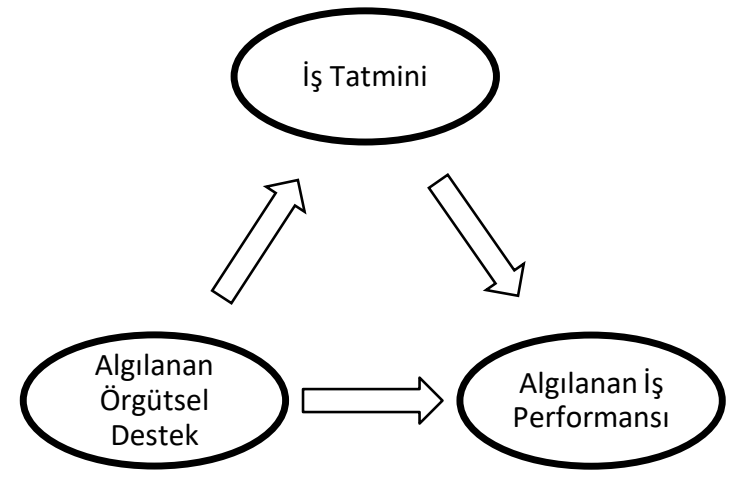

\section{Araştırmanın Metodolojisi}

\subsection{Araştırma Örneklemi ve Veri Toplama Yöntemi}

Bu çalışmada örnekleme yöntemi olarak olasılıklı olmayan örnekleme yöntemlerinden birisi olan "Elverişlilik Örneklemesi”" kullanılmıştır. İsminden de anlaşıldığı üzere elverişlilik örneklemi, araştırmacının ulaşabildiği katılımcılardan oluşmaktadır. Bu yöntem genellikle kitlenin homojen olduğunu ve katılımcıların birbirlerine benzediğini varsaymaktadır. 
Çalışmanın amaçlarına hizmet edebilmek ve hipotezlerini test edebilmek için, örneklem olarak Ankara'da faaliyet gösteren bir özel hastanede görev yapan hemşire ve sağlık destek personeli pozisyonunda çalışanlar seçilmiş ve araştırma bu katılımcılara uygulanmıştır.

Katılımcılara, anket sonucunda edinilecek olan veri ve sonuçların tamamen ve sadece akademik anlamda değerlendirileceği ve hiçbir kişi veya kuruluşa verilmeyeceği de açikça belirtilmiştir. Katılımcılara isim ve soyadı yazmamaları gerektiği de söylenmiş ve alınan bilgilerin çalıştıkları kurumla paylaşılmayacağına dair garanti de verilmiştir. 350 adet dağıtılan anketlerden, 276 adedi doldurularak teslim edilmiş olup; kullanılabilir durumda olan anket oran1 \%92'dir. Örneklemin nihai hali 253 sağlık çalışanından oluşmaktadır. Ankete katılan çalışanların yaklaşık \%85'i kadın, \%15'i erkek ve yaklaşık \%65'i 20-30 yaş aralığında olup; söz konusu kurumda çalışma sürelerinin ortalamas 5 y1l civarındadır.

Anket, katılımcıların cinsiyet, yaş ve kurumda çalıştıkları süre gibi demografik verilerini, algılanan örgütsel destek ölçeğini, iş tatmini ölçeğini ve algılanan iş performansı ölçeğini içeren dört bölümden oluşmaktadır.

\subsection{Kullanılan Ölçekler}

\subsubsection{Bağımsız Değişken: Algılanan Örgütsel Destek}

Bu çalışmada, çalışanların algılanan örgütsel destek ölçümünü yapabilmek için Rhoades ve diğerleri (2001) tarafindan geliştirilmiş olan ölçek kullanılmıştır. 4 maddeden oluşan bu ölçek, (1) “Tamamen Katılmıyorum”dan (5) “Tamamen Katılıyorum”a kadar sıralamaya sahip olan 5'li Likert ölçeğinde bireysel değerlendirmeye sunulmuştur. Bu ölçekte elde edilen puanların yüksekliği, algılanan örgütsel desteğin derecesi ile doğru orantılıdır. Ölçekten elde edilen puan ne kadar yüksekse, algılanan örgütsel desteğin derecesi de o oranda yüksektir.

\subsubsection{Bağımlı ve Aracı Değişken: İş Tatmini}

Robbins ve Judge (2009) iş tatmininin ölçümünde çoğunlukla kullanılan iki yaklaşım olduğunu belirtmiştir: 1) Bireylerin iş tatminleri üzerine tek soruyla genel bir değerlendirme yapması şeklinde olan "tek soruluk küresel değerlendirme" (Single Global Rating) yaklaşımı ve 2) belirlenen önemli iş beklentileri konusunda çalışanların duygularını sorgulayan "toplam skor" (Summation Score) yaklaşımı. İki yöntemi karşılaştıran çalışmalar genellikle her ikisinin de geçerlilik konusunda birbirlerine karşı üstünlükleri olmadığını ortaya koymuştur (Nagy, 2002; Dolbier ve ark., 2005).

Bu araştırmada katılımcilara, Scarpello ve Campbell'in (1983) önerdiği tek maddelik genel değerlendirme ifadesi olan "Her şeyi bir arada göz önüne aldığınızda, işinizden ne kadar memnunsunuz?" sorusu sorulmuştur. Soruya verilen cevap (1) "Hiç memnun değilim"den (5) "Çok memnunum"a kadar olan 5'li Likert ölçeği yelpazesinde bireysel olarak değerlendirilmiştir. Bu sorudan elde edilen puanların yüksekliği, iş tatmini düzeyi ile doğru orantılıdır. Sonuçta bireyin soru puanı ne kadar yüksekse, iş tatmini de o oranda yüksektir.

\subsubsection{Bağımlı Değişken: Algılanan İş Performansı}

Behrman ve Perreault'a (1984) göre, iş performansı dört farklı şekilde değerlendirilebilir: (a) bireysel değerlendirme, (b) iş arkadaşları tarafından yapılan değerlendirme (c) amirler tarafından yapılan değerlendirme (d) müşteri değerlendirmesi.

Katılımcıların algıladıkları bireysel iş performansları Darwish'in (2000) 4 maddeden oluşan ölçeği ile ölçülmüştür. Bu ölçekteki her bir madde (1) "Çok düşük"den (5) "Çok yüksek"e kadar sıralamaya sahip olan 5'li Likert ölçeğinde bireysel değerlendirmeye sunulmuştur. Bu ölçekte elde edilen puanların yüksekliği, algılanan iş performansı seviyesi ile doğru orantılıdır. Ölçekten elde edilen puan ne kadar yüksekse algılanan iş performansı seviyesi de o oranda yüksektir. 
Algılanan Örgütsel Destek ile Algılanan İş Performansı Arasındaki İlişkide İş Tatmininin...

Tablo 1: Ankette Kullanılan Ölçeklerin Cronbach Alfa katsayıları

\begin{tabular}{ll}
\hline Ölçekler & Cronbach Alfa Katsayısı $(\boldsymbol{\alpha})$ \\
\hline Algılanan Örgütsel Destek & 0,95 \\
Algıllanan İș Performansı & 0,77 \\
\hline
\end{tabular}

Ankette kullanılan ölçeklerin güvenilirlik katsayıları Tablo 1'de görülmektedir. Tablodan da anlaşılacağı üzere, algılanan örgütsel destek ve algılanan iş performansı ölçeklerinin Cronbach alfa katsayıları Nunnally ve Bernstein (1994) tarafindan en düşük değer olarak önerilen 0,70 değerinin üzerindedir. Bu durumda, kullanılan ölçeklerin güvenilir olduğunu söylemek mümkündür.

\subsection{Araştırmanın Hipotezlerinin Test Edilmesi}

Araştırmanın hipotezlerinin test edilmesi amacıyla öncelikle temel değişkenlerin birbirleriyle ilişkili olup olmadığını ve olası ilişkilerinin yön ve kuvvet derecelerinin tespit edilmesi amacıyla korelasyon analizi yapılmıştır. Tablo 2'de araştırma modelinin değişkenleri arasındaki ilişkileri gösteren korelasyon matris tablosu yer almaktadır.

Tablo 2: Korelasyon Matris Tablosu

\begin{tabular}{|c|c|c|c|c|}
\hline & & $\begin{array}{c}\text { Algılanan Örgütsel } \\
\text { Destek }\end{array}$ & İş Tatmini & $\begin{array}{l}\text { Algilanan İş } \\
\text { Performansi }\end{array}$ \\
\hline \multirow[t]{3}{*}{$\begin{array}{l}\text { Algılanan Örgütsel } \\
\text { Destek }\end{array}$} & $\begin{array}{l}\text { Pearson } \\
\text { Correlation }\end{array}$ & 1 &, $537^{* *}$ &, $132^{\prime}$ \\
\hline & Sig. (2-tailed) & & ,000 & ,03 \\
\hline & $\mathrm{N}$ & 253 & 253 & 25 \\
\hline \multirow[t]{3}{*}{ İş Tatmini } & $\begin{array}{l}\text { Pearson } \\
\text { Correlation }\end{array}$ & ,537** & 1 &, $343^{*}$ \\
\hline & Sig. (2-tailed) &, 000 & & 00 \\
\hline & $\mathrm{N}$ & 253 & 253 & 253 \\
\hline \multirow[t]{3}{*}{$\begin{array}{l}\text { Algılanan İş } \\
\text { Performansı }\end{array}$} & $\begin{array}{l}\text { Pearson } \\
\text { Correlation }\end{array}$ & ,132" &, $343^{* *}$ & \\
\hline & Sig. (2-tailed) &, 036 &, 000 & \\
\hline & $\mathrm{N}$ & 253 & 253 & 25 \\
\hline
\end{tabular}

** Korelasyon 0.01 düzeyinde anlamlıdır.

* Korelasyon 0.05 düzeyinde anlamlıdır.

Korelasyon matris tablosu incelendiğinde, çalışmanın üç önemli değişkeni arasındaki ilişkiler ortaya çıkmaktadır. Tabloya bakıldığında, algılanan örgütsel destek ile hem iş tatmini hem de algılanan iş performansı arasında olumlu yönde bir ilişkinin varlığı göze çarpmaktadır. Aynı zamanda, iş tatmini ile iş performansı arasında da olumlu yönde bir ilişki dikkat çekmektedir. Tüm bu bulgular araştırma hipotezlerinin daha derinlemesine araştırılması gerektiğini gösterir niteliktedir. $\mathrm{Bu}$ sebeple, SPSS programında hiyerarşik regresyon analizi gerçekleştirilmiştir. Yapılan hiyerarşik regresyonu Tablo 3'te yer almaktadır.

Üçüncü hipotezde yer alan aracılık rolünün tespit edilebilmesi için Baron ve Kenny'nin (1986) öne sürdüğü bazı koşulların sağlanıp sağlanmadığına bakılmıştır. Bu koşullara göre; bağımsız değişken ile bağımlı değişken arasında anlamlı bir ilişki olması; bağımsız değişken ile aracı değişken arasında anlamlı bir ilişki olması; aracı değişken ile bağımlı değişken arasında anlamlı bir ilişki olması ve aracı ve bağımsız değişkenin beraber analize girmesi sonucunda, bağımsız değişkenin 
bağımlı değişken üzerindeki etkisinin azalması ya da bu etkinin tamamen ortadan kalkması gerekmektedir. Bu koşullar sağlanamadığı takdirde aracılık etkisinden söz etmek mümkün değildir (Baron ve Kenny, 1986). Aracılık koşullarının gerçekleşip gerçekleşmediğini ve aynı zamanda araştırma hipotezlerinin doğrulanıp doğrulanmadığını test edebilmek için yapılmış olan hiyerarşik regresyon analizinin sonuçları Tablo3'te yer almaktadır.

Tablo 3: Hiyerarşik Regresyon Sonuçları

\begin{tabular}{|c|c|c|c|c|c|}
\hline Değişsenler & $\mathbf{R}^{2}$ & $\mathbf{F}$ & B & $\beta$ & $\mathbf{P}$ \\
\hline \multicolumn{6}{|l|}{ 1. Aşama } \\
\hline Model1 & 0,289 & 101,795 & & & \\
\hline Sabit Değer & & & 1,929 & & 0,000 \\
\hline Algılanan Örgütsel Destek & & & 0,476 & 0,537 & $0,000 *$ \\
\hline \multicolumn{6}{|l|}{ Bağımlı Değişken: İş Tatmini } \\
\hline \multicolumn{6}{|l|}{ 2.Aşama } \\
\hline Model2 & 0,118 & 33,519 & & & \\
\hline Sabit Değer & & & 2,534 & & 0,000 \\
\hline İş Tatmini & & & 0,288 & 0,343 & $0,000^{*}$ \\
\hline \multicolumn{6}{|c|}{ Bağımlı Değişken: İş Performansı } \\
\hline \multicolumn{6}{|l|}{ 3.Aşama } \\
\hline Model3 & 0,17 & 4,452 & & & \\
\hline Sabit Değer & & & 3,229 & & 0,000 \\
\hline Algılanan Örgütsel Destek & & & 0,098 & 0,132 & $0,036^{*}$ \\
\hline \multicolumn{6}{|c|}{ Bağımlı Değişken: İş Performansı } \\
\hline \multicolumn{6}{|l|}{ 4.Aşama } \\
\hline Model4 & 0,122 & 17,314 & & & \\
\hline Sabit Değer & & & 2,611 & & 0,000 \\
\hline Algılanan Örgütsel Destek & & & $-0,055$ & $-0,074$ & 0,296 \\
\hline İş Tatmini & & & 0,321 & 0,383 & $0,000^{*}$ \\
\hline Bağımlı Değişken: İş Perfor & & & & & \\
\hline
\end{tabular}

Tablo 3'te yer alan bulgulara göre, bağımsız değişken olan algılanan iş performansı ile aracı değişken olan iş tatmini arasında olumlu ve anlamlı bir ilişki olduğu görülmektedir $(\beta=0,537 ; p=$ 0,000). Bu durumda, hem Baron ve Kenny'nin (1986) aracılık modelinin ilk koşulu gerçekleştirilmiş, hem de araştırmanın ilk hipotezi (H1) doğrulanmış olmaktadır. Yine Tablo 3'e göre, aracı değişken olan iş tatmini ile bağımlı değişken olan algılanan iş performansı arasında olumlu ve anlamlı bir ilişki tespit edilmiştir $(\beta=0,343 ; p=0,000)$. Böylece modelin ikinci koşulu da sağlanırken, aynı zamanda araştırmanın ikinci hipotezi de $(\mathrm{H} 2)$ doğrulanmış olmuştur. Regresyon analizinin diğer sonuçlarına göre, bağımsız değişken olan algılanan örgütsel destek ile bağımlı değişken olan algılanan iş performansı arasında da olumlu ve anlamlı bir ilişki olduğu anlaşılmaktadır $(\beta=0,132 ; p=0,036)$. Dolayısıyla, modelin üçüncü şartı ve araştırmanın üçüncü hipotezi (H3) onaylanmış olmaktadır.

Son olarak regresyon analizinde, iş tatmininin algılanan örgütsel performans ile algılanan iş performansı arasında aracı rolü olup olmadığını test etmek için, her iki bağımsı değişken birlikte 
regresyona dahil edilmiştir. Bu yapılan işlemin sonucuna göre, model4'deki beta katsayısının $(\beta=-$ $0,074)$, model3'teki beta katsayısından $(\beta=0,132)$ oldukça daha küçük olduğu ve asıl önemli olan model3'te görülen algılanan örgütsel desteğin algılanan iş performansı üzerindeki anlamlı etkisinin $(\mathrm{p}=0,036<0,05)$, model4'te istatistiksel olarak anlamsız hale geldiği $(\mathrm{p}=0,296>0,05)$ görülmektedir. Bu durumda, aracılık modelinin son koşulu da gerçekleşmiş olmaktadır. Aynı zamanda, araştırmanın dördüncü hipotezi (H4) de doğrulanmış; algılanan örgütsel destek ile algılanan iş performansı arasındaki ilişkide iş tatminin "tam aracılık" etkisine sahip olduğu tespit edilmiştir.

\section{Sonuç ve Tartışma}

Araştırma hipotezlerinin test edilmesi sonucunda elde edilmiş olan bulgular geçmiş literatürde yapılmış olan çalışmalar ile paralel sonuçlar göstermektedir (Örn.: Robert vd., 2009; Fu vd., 2013). Buna göre, öncelikle araştırmanın ilk hipotezi olan algılanan örgütsel destek ile iş tatmini arasında beklenen olumlu ve anlamlı ilişki doğrulanmıştır. Bu sonuç, araştırma yapılan hastanedeki sağlık çalışanlarının örgütsel destek algılarının arttıkça iş tatmin düzeylerinin yükseldiğini ve benzer şekilde örgütsel destek algıları azaldıkça iş tatmin düzeylerinin azaldığını ortaya koymaktadır.

Araştırmanın ikinci hipotezi olan iş tatmini ile algılanan iş performansı arasında beklenen olumlu ve anlamlı bir ilişkinin varlığı da, yapılan analiz sonucunda doğrulanmıștır. Bu sonuç da geçmiş literatürde yapılan araştırma sonuçlarıyla uyum göstermektedir (örn.: Harrison vd., 2006; Bowling, 2007; Riketta, 2008). Buna göre, araştırma yapılan hastanedeki sağl1k çalışanlarının iş tatmin düzeyleri yükseldikçe, kendi algılarına göre iş performanslarının arttığı ve buna paralel şekilde iş tatmin düzeyleri düştükçe, kendi algılarına göre iş performanslarının azaldığı anlaşılmaktadır.

Araştırmanın üçüncü hipotezi olan algılanan örgütsel destek ile iş performansı arasında beklenen olumlu ve anlamlı ilişkinin varlığ 1 da, yapılan analiz sonucunda onaylanmıştır. Literatürde daha önce iki değişken arasında yapılan çalışmalarda da benzer sonuçlar görülmektedir (Örn.: Cullen vd., 2014; Guan vd., 2014). Buna göre, araştırma yapılan hastanedeki sağlık çalışanlarının çalıştıkları kurumdan algıladıkları destek düzeyi arttıkça kendi algılarına göre iş performansları da yükselmekte ve benzer şekilde çalıştıkları kurumdan algıladıkları destek düzeyi azaldıkça kendi algılarına göre iş performansları da düşmektedir. Bu durum literatürde, çalışanların hem destek aldığı örgüte faydalı bir karşılık sunma çabası ile hem de artan performanslarının örgüt tarafından görüleceği ve ödüllendirileceğine dair inançları ile açıklanmaktadır (Guan vd., 2014).

Araştırmanın dördüncü hipotezi olan algılanan örgütsel destek ile iş performansı arasındaki ilişkide iş tatmininin beklenen aracı rolünün varlığı da yapılan analiz sonucunda doğrulanmıştır. Yapılan hiyerarşik regresyon analizinden elde edilen bulgulara göre, araştırma yapılan hastanedeki sağlık çalışanlarının çalıştıkları kurumdan algıladıkları destek düzeyinin kendi değerlendirdikleri performans düzeyine olan olumlu etkisinde iş tatmini "tam aracı" rol oynamaktadır. Tam aracılık etkisi, aracı devreye girdiği zaman, bağımsız değişkenin bağımlı değişken üzerinde etkisinin ortadan kalktığını; yani aracı değişken olmadan bağımsız değiş̧ken ile bağımlı değişken arasında bir ilişki olamayacağını ifade eder. Buna göre, araştırma yapılan hastanedeki sağlık çalışanlarının çalıştıkları kurumdan algıladıkları destek düzeyinin kendi değerlendirdikleri performans düzeyine olan olumlu etkisinin iş tatmini sayesinde olduğu ortaya çıkmaktadır. İş tatmini düşük olduğunda bu ilişki zayıflamakta, yüksek olduğunda ise bu ilişki güçlenmektedir. Sonuç olarak bu örneklem için, iş tatmini olmadığı zaman ise, algılanan örgütsel destek iş performansını etkilememektedir.

Sosyal Değişim Teorisi'nin temel dayanağı, sosyal ilişkilerde ve özellikle çalışan-örgüt ilişkisinde karşılıklılık prensibidir (Blau, 1964). Çalışanlar örgütlerinden destek aldıklarını hissettikleri zaman, iş memnuniyetleri artmakta ve dolayısıyla bu memnuniyete ve aldıkları desteğe karşılık olarak örgütlerine daha faydalı olabilmek ve kendilerinden bekleneni olabildiğince yerine getirebilmek için daha çok çaba sarf etmeleri de bu prensibe uygun bir alg1-tutum-davranış zinciridir. Elbette iş tatminin tek öncülü algılanan örgütsel destek değildir. Ancak bu çalışmadan elde edilen 
sonuçlara göre, algılanan örgütsel desteğin iş tatminine katkıda bulunduğu durumlarda, iş tatmininin de önemli ölçüde iş performansına etki ettiği ileri sürülebilir. Söz konusu etkileşim ve aracılık etkisinin farklı sektör ve örneklemler üzerinde araştırılması, yukarıda yapılan yorumların aydınlatılması ve konunun netleştirilmesi açısından faydalı olacaktır.

\section{Araştırmanın Kısıtları}

$\mathrm{Bu}$ çalışmanın da yapılan her çalışmada olduğu gibi bir takım kısıtları bulunmaktadır. Öncelikle örnekleme yöntemi olarak olasılıklı olmayan örnekleme yöntemlerinden "elverişlilik örneklemesi"nin kullanılmış olması, araştırma sonuçlarının evreni ne kadar temsil ettiği konusunda bir belirsizliğe sebep olabilmektedir. Çünkü elverişlilik örneklemesinde kitlenin homojen olduğu varsayılarak, araştırmacının ulaşabildiği katılımcıların evreni doğru temsil ettiğini kabul etmektedir. $\mathrm{Bu}$ sebepten dolayı, bu araştırmanın sonuçlarının tüm sağlık sektörüne genelleştirilmesi doğru olmayabilir.

Çalışmanın bir başka kısıtı ise, ölçeklerin bireysel değerlendirmeye dayalı olmasıdır. Bireysel değerlendirmelerde bireylerin kendilerini olduklarından daha iyi gösterme eğilimleri olduğu bilinmektedir (Schwarz, 1999). Ancak bu çalışmanın değişkenlerinin kişisel algı ifade ediyor olması sebebiyle, bu durumun sonuçları çok fazla etkileyeceği düşünülmemektedir. Bireylerin kendilerini olduklarından daha iyi ifade etmeye çalışabilecekleri tek değişken "algılanan iş performansı" olup; o da zaten bireysel anlamda kendilerini nasıl algıladıklarını yansıttığı için, göreceli anlamda değerlendirildiğinde, kişisel abartıların sonuçları önemli düzeyde etkilememesi beklenmektedir.

\section{Kaynakça}

Ahmad, Z. A., ve Yekta, Z. A. (2010). Relationship between perceived organizational support, leadership behavior, and job satisfaction: An empirical study in Iran. Intangible Capital, 6(2), 162-184.

Armeli, S., Eisenberger, R., Fasolo, P. ve Lynch, P. (1998). Perceived organizational support and police performance: The moderating influence of socioemotional needs. Journal of Applied Psychology, 83, 288-297.

Baron, R. M. ve Kenny, D. A. (1986). The moderator\{mediator variable distinction in social psychological research: Conceptual, strategic, and statistical considerations. Journal of personality and social psychology, 51(6):1173.

Behrman, D. N. ve Perreault, W. D., Jr (1984). A role stress model of the performance and satisfaction of industrial salespersons. Journal of Marketing, 48(4), 9-21.

Blau, P. M. (1964). Exchange and power in social life. New York: Wiley.

Borman, W. C. ve Motowidlo, S. J. (1993). Expanding the criterion domain to include elements of contextual performance. In N. Schmitt \& W. C. Borman (Eds.), Personnel selection in organizations (pp. 71-98). San Francisco: CA: Jossey-Bass.

Bowling, N. A. (2007). Is the job satisfaction-job performance relationship spurious? A metaanalytic examination. Journal of Vocational Behavior, 71, 167-185.

Byrne, Z. S. ve Hochwarter, W. A. (2008). Perceived organizational support and performance. Journal of Managerial Psychology, 23, 54-72.

Christen, M., Iyer, G. and Soberman, D. (2006). Job Satisfaction, Job Performance, and Effort: A Reexamination Using Agency Theory, Journal of Marketing, Januaryr, Vol. 70, pp. 137-150. 
Cullen, K. L., Edwards, B. D., Casper, W. C. Ve Gue, K. R. (2014). Employees' adaptability and perceptions of change-related uncertainty: Implications for perceived organisational support, job satisfaction, and performance. Journal of Business and Psychology, 29(2), 269-280.

Dolbier, C.L., Webster, J.A., McCalister, K.T., Mallon, M.W. ve Steinhardt, M.A. (2005) Reliability and Validity of a Single-item Measure of Job Satisfaction. Am. J. Health Promot. 19, 194198.

Ehsani, M., Sofdel, H. S., Amiri, M., Masrur, F. F. ve Hossini, N. S. (2013). Relationship between perceived organizational support with job satisfaction and organizational commitment of sports departments staff. International Journal of Sport Studies, 3(12), 1302-1306.

Eisenberger, R., Huntington, R., Hutchison, S. ve Sowa, D. (1986). Perceived organizational support. Journal of Applied Psychology, 71, 500-507

Eisenberger, R., Cummings, J., Armeli, S. ve Lynch, P. (1997). Perceived organizational support, discretionary treatment, and job satisfaction. Journal of Applied Psychology, 82(5), 812-820.

Fisher, C. D. (2003). Why do lay people believe that satisfaction and performance are correlated? Possible sources of a commonsense theory. Journal of Organizational Behavior, 24(6), 753777.

Fu, J., Sun, W., Wang, Y., Yang, X. ve Wang, L. (2013). Improving job satisfaction of Chinese doctors: the positive effects of perceived organizational support and psychological capital. Public Health. 127, 10: 946-951, Elsevier.

Guan, X., Sun, T., Hou, Y., Zhaou, L., Luan, Y. ve Fan, L. (2014). The relationship between job performance and perceived organizational support in faculty members at Chinese universities: a questionnaire survey. BMC Medical Education, 14(50), 1-10.

Harrison, D. A., Newman, D. A. ve Roth, P. L. (2006). How important are job attitudes? Metaanalytic comparisonsof integrative behavioral outcomes and time sequences. Academy of Management Journal,49,305-325.

Heskett, J. L., Jones, T., Loveman, S., Sasser, J. W. E. ve Schlesinger, L. A. (1994). Putting the service-profit chain to work. Harvard Business Review, 72(2), 164.

Hulin, C. L. Ve Judge, T. A. (2003). Job attit Udes. In W. C. Borman, D. R. ligen, and R. J. Klimoski (Eds.), Handbook of Psychology: Industrial and Organizational Psychology (pp. 255-276). Hoboken, NJ: Wiley.

Janssen, O., Van de Vliert, E. ve West, M. (2004). The bright and dark sides of individual and group innovation: A special issue introduction. Journal of Organisational Behavior, 25, 129-145.

Judge, T. A., Thoresen, C. J., Bono, J. E. ve Patton, G. K. (2001). The job satisfaction-job performance relationship: a qualitative and quantitative review. Psychological Bulletin, 127, $376-407$.

Kwak, C., Yae, B., Xu, Y. ve Eun, J.C. (2010). International Journal of Nursing Studies Relationship of job satisfaction with perceived organizational support and quality of care among South Korean nurses: A questionnaire survey. International Journal of Nursing Studies, 47, 12921298.

Locke, E. A. (1976). The nature and causes of job satisfaction. Handbook of industrial and organizational psychology, 1:1297-1343. 
Miao, R. ve Kim, H. (2010). "Perceived Organizational Support, Job Satisfaction and Employee Performance: An Chinese Empirical Study," Journal of Service Science and Management, Vol. 3 No. 2, pp. 257-264.

Mirvis, P. H. ve Lawler, E. E., III. (1977). Measuring the financial impact of employee attitudes. Journal of Applied Psychology, 62(1), 1-8.

Mullins, L.J, (1996), "Management and Organizational Behaviour”, Fourth ed., Pitmon Publishing, London.

Nagy, M.S. (2002) Using a Single-Item Approach to Measure Facet Job Satisfaction. Journal of Occupational and Organizational Psychology, 75, 77-86.

Nunnally, J. ve Bernstein, I. (1994). Psychometric Theory. 3rd edition. New York: McGraw Hill.

Organ, D. W. (1977). A reappraisal and reinterpretation of the satisfaction-causes-performance hypothesis. The Academy of Management Review, 2(1), 46-53.

Rhoades, L., Eisenberger, R. ve Armeli, S. (2001), "Affective commitment to the organization: the contribution of perceived organizational support", Journal of Applied Psychology, Vol. 86, pp. 825-36.

Rhoades, L. ve Eisenberger, R. (2002). Perceived organizational support: a review of the literature. Journal of applied psychology, 87(4):698.

Riggle, R. J., Edmondson, D. R. ve Hansen, J. D. (2009). A meta-analysis of the relationship between perceived organizational support and job outcomes: 20 years of research. Journal of Business Research, 62: 1027-1030.

Riketta, M. (2008). The causal relation between job attitudes and performance: A meta-analysis of panel studies. Journal of Applied Psychology,93,472-481.

Robbins, S. P., ve Judge, T. (2009). Organizational behavior. Upper Saddle River, N.J: Pearson/Prentice Hall.

Robert, R. J., Diane, E. R., John, H. D. (2009) A meta-analysis of the relationship between perceived organizational support and job outcomes: 20 years of research. Journal of Business Research, 62:1027-1030

Rousseau, D. M., ve P. J. McLean. (1993) “The Contracts of Individuals and Organizations", Research in Organizational Behavior, no. 15: 1-43.

Rutherford, B. B., Boles, J. S., Hamwi, G. A., ve Rutherford, L. G. (2009). Perceived organizational support and the seven facets of salesperson job satisfaction. Journal of Selling and Major Account Management, 28 (4), 387-401.

Scarpello, V. ve Campbell, J.P. (1983), "Job Satisfaction: are all the parts there?" Personal Pschology, Vol.36, pp.557-600.

Schwarz, N. (1999). Self-reports: How the questions shape the answers. American Psychologist, 54, 93-105.

Shore, L. M., ve Shore, T. H. (1995). Perceived organizational support and organizational justice. In R. S. Cropanzano \& K. M. Kacmar (Eds.), Organizational politics, justice, and support: Managing the social climate of the workplace: 149-164. Westport, CT: Quorum.

Shore, L. M., ve Wayne, S. J. (1993). Commitment and employee behavior: comparison of affective organizational commitment and continuance commitment at perceived organizational support. Journal of Applied Psychology, 78, 774-780. 
Smith, P. C., ve Cranny, C. (1968). Psychology of men at work. Annual Review of Psychology, 19, 467-496.

Spector, P. E. (1985). Measurement of human service and satisfaction: Development of the job satisfaction survey. American journal of community psychology, 13(6):693-713.

Spector, P.E. (1997). Job satisfaction: Application, assessment, causes and conseque- nces. Thousand Oaks, CA: SAGE

Walster E, Berscheid E, Walster GW: New directions in equity research. Journal of Personality and Social Psychology, 1973, 25(2):151.

Wann-Yih, W. ve Htaik, S. (2011) "The Impacts of Perceived Organizational Support, Job Satisfaction and Organizational Commitment on Job Performance in Hotel Industry", The 11th International DSI and the 16th APDSI Joint Meeting, July 12-16 2011, Taiwan.

Williams, L. J., ve Podsakoff, P. M. (1989). Longitudinal-field methods for studying reciprocal relationships in organizational-behavior research-toward improved causal-analysis. Research in Organizational Behavior, 11, 247-292.

Williams, R. S., Managing Employee Performance: Design and Implementation in Organizations. London, UK: Thompson Learning, 2002.

Witt, L. A. ve Carlson, D. S. (2006). The work-family interface and job performance: Moderating effects of conscientiousness and perceived organizational support. Journal of Occupational Health Psychology, 11(4), 343-357. 